\title{
Estudo retrospectivo de casos caninos de leishmaniose atendidos na cidade de São Paulo, Brasil (1997-2007)
}

\section{Retrospective study of canine cases of leishmaniasis attended in São Paulo, Brazil (1997-2007)}

\author{
Márcia Cristina Sonoda ${ }^{1}$; Claudio Nazaretian Rossi ${ }^{1}$; \\ Márcia Dalastra Laurenti²; Carlos Eduardo Larsson ${ }^{3 *}$
}

\section{Resumo}

\begin{abstract}
A leishmaniose constitui-se em zoonose causada por protozoário pleomórfico do gênero Leishmania. Em face da magnitude de alastramentro da doença no Brasil, foi realizado um levantamento retrospectivo de casos de leishmaniose canina diagnosticados nos Serviços de Dermatologia e de Clínica Médica de cães e gatos do HOVET/USP. A amostragem compôs-se de 36 casos caninos naturalmente infectados por Leishmania sp, cujo diagnóstico fora estabelecido pela caracterização por pelos dados anamnésticos, de exames físico e dermatológico, complementados por exames hematológicos, bioquímicos e imagéticos, afora sorologia (Ensaio Imunoenzimático Indireto - ELISA e/ou Reação de Imunofluorescência Indireta - RIFI), histopatologia de pele e/ou pela evidenciação do protozoário em exames parasitológicos de biópsia aspirativa de linfonodos e/ou medula óssea e pela técnica de imuno-histoquímica. Não houve predisposição por um determinado sexo; a faixa etária (52,8\%) mais prevalente foi aquela dos 13 a 48 meses de vida, com maior acometimento de cães de raça definida $(66,7 \%)$, principalmente Poodles e Labradores (20,8\% cada). Pôde-se concluir que todos os casos foram alóctones. Quanto aos municípios de origem os animais provieram de: Campinas, Campo Limpo Paulista, Holambra, Ilha Bela, São Roque, Sorocaba, Ubatuba e Uberaba (um caso / município). Os demais 28 cães do Estado de São Paulo originaram-se de municípios com transmissão: canina e humana (Araçatuba - três, Bauru - um), canina (Cotia - cinco, Embu - quatro) ou sob investigação (São Paulo - 11, Mogi das Cruzes - um). Já Portugal (um) e Minas Gerais (Belo Horizonte - dois) são locais caracterizados como de transmissão canina e humana. Puderam-se evidenciar deslocamentos breves ou longos a 14 municípios paulistas (Araçatuba, Birigui, Caraguatatuba, Cotia, Eldorado, Embu e Embu Guaçu, Guarujá, Ilha Bela, Itapecerica da Serra, Peruíbe, Presidente Prudente, São Roque e São Paulo) e a cinco Estados (Maranhão, Minas Gerais, Paraná, Rio de Janeiro e Santa Catarina). De acordo com a classificação sintomatológica, $50 \%$ eram oligossintomáticos, $47,2 \%$ sintomáticos e $2,8 \%$ assintomáticos.
\end{abstract}

Palavras-chave: Leishmaniose, cães, epidemiologia, aspectos clínicos

\footnotetext{
Abstract

Leishmaniasis is zoonosis caused by pleomorphic protozoa of the genus Leishmania. The spread of the disease in Brazil lead to this retrospective survey of canine visceral leishmaniasis diagnosed at the Service of Dermatology and Medical Clinics of the Small Animal Hospital-USP. We evaluated the records of 36

${ }^{1}$ Discente(s) do Programa de Pós-Graduação em Clínica Veterinária, Dept ${ }^{\circ}$ de Clínica Médica, Faculdade de Medicina Veterinária e Zootecnia da Universidade de São Paulo, FMVZ/USP, São Paulo, SP. E-mail: mcsonoda@hotmail.com; claudiorossi@usp.br

2 Prof. Dr. Associado do Dept ${ }^{\circ}$ de Patologia da Faculdade de Medicina, Universidade de São Paulo, FMVZ/USP, São Paulo, SP. E-mail: mdlauren@usp.br

${ }^{3}$ Prof. Titular do Dept ${ }^{\circ}$ de Clínica Médica da Faculdade de Medicina Veterinária e Zootecnia, FMVZ/SP, São Paulo, SP. E-mail: larsderm@usp.br

* Autor para correspondência
} 
dogs naturally infected with Leishmania sp, which diagnosis included disease characterization during anamnesis, physical and dermatologic examination, hematology, biochemistry, imaging, serology (Enzyme-Linked Immunosorbent Assay - ELISA and/or Indirect Fluorescent Reaction - RIFI), skin histopathology and/or agent isolation from aspiration biopsy samples of lymph nodes and/or bone marrow, and immunohistochemistry. All cases were allochtonous without gender predilection; $52.8 \%$ were 13 to 48 months old, with greater occurrence in pure breed dogs $(66,7 \%)$, mostly Poodles and Labradors (20.8\% each). Regarding origin: Campinas, Campo Limpo Paulista, Holambra, Ilha Bela, São Roque, Sorocaba, Ubatuba and Uberaba (one case / city). The remaining 28 cases from the State of São Paulo were located in cities with reported canine-human transmission (Araçatuba - three, Bauru - one), intra-canine transmission (Cotia - five, Embu - four) or cities under investigation (São Paulo - 11, Mogi das Cruzes - one). Portugal (one) and Minas Gerais (Belo Horizonte - two) reported caninehuman transmission. Prior to the leishmaniasis development dogs remained for short or long periods in 14 cities in the State of São Paulo (Araçatuba, Birigui, Caraguatatuba, Cotia, Eldorado, Embu e Embu Guaçu, Guarujá, Ilha Bela, Itapecerica da Serra, Peruíbe, Presidente Prudente, São Roque and São Paulo) and five other Brazilian States (Maranhão, Minas Gerais, Paraná, Rio de Janeiro and Santa Catarina. Most animals were oligosymptomatic (50\%), $47.2 \%$ symptomatic and $2.8 \%$ asymptomatic.

Key words: Leishmaniasis, dog, epidemiology, clinical aspects

\section{Introdução}

A leishmaniose é enfermidade infecciosa zoonótica de caráter crônico, de distribuição mundial, causada por protozoário pleomórfico da ordem Kinetoplastida, família Trypanosomatidae, gênero Leishmania. Inclui várias espécies que eliciam manifestações viscerais e cutâneas, que, classicamente, são subdivididas em duas formas: leishmaniose tegumentar, que apresenta manifestação cutânea, mucocutânea ou cutânea difusa e leishmaniose visceral, com alterações sistêmicas e por vezes cutâneas (MICHALSKY et al., 2002), comuns no cão e no homem (FEITOSA et al., 2000; MARCONDES, 2013).

No ambiente doméstico, o cão é considerado o principal reservatório (SLAPPENDEL; FERRER, 1998; MILLER; GRIFFIN; CAMPBELL, 2013) pelo fato da prevalência canina ser alta em áreas endêmicas, bem como, por preceder a ocorrência de casos humanos. Afora isso, o mais preocupante é que muitos cães infectados não apresentam sintomatologia da doença, porém podem albergar parasitas na derme (SANTA ROSA; OLIVEIRA, 1997).

A sintomatologia da infecção canina apresenta o mesmo espectro de variação que a humana e, de acordo com alguns autores (MANCIANTI et al.,
1988; SANTA ROSA; OLIVEIRA, 1997), os cães soropositivos podem ser classificados clinicamente como assintomáticos (não apresentam manifestações clínicas da infecção), oligossintomáticos (podem apresentar sintomatologia clínica e/ou tegumentar, com até três tipos de manifestações) e sintomáticos (demonstram mais de três manifestações clínicas características da doença, com ou sem comprometimento tegumentar). $\mathrm{Na}$ atualidade discute-se e se põem em dúvida a validade de tal critério classificatório (MARCONDES, 2013).

Devido à variedade de sintomas da doença, o diagnóstico clínico da leishmaniose canina é difícil, sendo que os achados clínicos não são característicos da doença, podendo-se aventar diversas outras enfermidades. Dessa forma, faz-se necessário a utilização de exames laboratoriais, tais como, sorológicos, parasitológicos, imuno-histoquímicos e moleculares para se diagnosticar tal enfermidade (FEITOSA et al., 2000). Ainda mais, a correlação com critérios epidemiológicos também contribui para a consecução de diagnóstico (BADARÓ; DUARTE, 1996).

Em face da crescente magnitude de ocorrência da leishmaniose canina no contexto da medicina veterinária e humana, julga-se oportuno o presente estudo, que tem por objetivo reunir informações 
relativas às leishmanioses, permitindo não só uma melhor compreensão, mas, também, uma visão mais abrangente desta enfermidade no tocante à epidemiologia e aos seus aspectos clínicos no Estado de São Paulo.

\section{Material e Métodos}

\section{Levantamento da casuística}

Realizou-se estudo retrospectivo dos casos da protozoose atendidos entre os meses de março de 1997 a março de 2007 nos Serviços de Dermatologia e de Clínica Médica de cães e gatos do Hospital Veterinário (HOVET) da Faculdade de Medicina Veterinária e Zootecnia da Universidade de São Paulo (FMVZ-USP), visando o resgate do número de registro de prontuários dos animais acometidos por leishmaniose. Posteriormente, realizou-se levantamento dos dados neles dispostos para obtenção de informações relativas à espécie; definição racial; idade; sexo; peso e dados anamnésticos; dos exames físico geral e dermatológico, visando a caracterização das alterações dermatológicas e/ou sistêmicas bem como os locais de origem, criação e de possíveis deslocamentos.

A amostragem foi composta por 36 caninos domésticos naturalmente acometidos por leishmaniose e com diagnóstico estabelecido por meio da técnica de ELISA e/ou pela RIFI. Além dos métodos sorológicos, em alguns dos cães envolvidos no estudo fora realizado o exame parasitológico direto de material colhido por punção aspirativa de linfonodos e/ou medula óssea, bem como histopatológico e imuno-histoquímico de amostras oriundas de pele lesada.

Coligiram-se, também, de todos os prontuários, os resultados de exames laboratoriais, tais como: hemograma (eritrograma e leucograma), contagem de plaquetas, exame de urina e da avaliação bioquímica (determinação de proteína sérica total, albumina, fosfatase alcalina, alanina aminotransferase - ALT - e das dosagens séricas de uréia e creatinina).

\section{Diagnóstico sorológico}

Os testes sorológicos empregados, preconizados pelo Ministério da Saúde (BRASIL, 2006), foram o teste de ELISA, efetuado como descrito por Colombo et al. (2011), sendo que as amostras foram testadas por método in house frente ao antígeno obtido a partir de promastigotas de Leishmania infantum (syn chagasi). As microplacas foram cobertas com antígeno total de parasitos, em concentração de 20 $\mu \mathrm{g} / \mathrm{mL}$ de proteína em tampão carbonato $0,05 \mathrm{M}$, pH 9,6, e incubadas “overnight" a $4^{\circ} \mathrm{C}$. Em seguida, foram lavadas com PBS-tween por três vezes e, posteriormente, bloqueadas com $200 \mu \mathrm{L}$ de PBSBSA $1 \%$ à temperatura ambiente durante duas horas. Após nova lavagem com PBS-tween por três vezes, $100 \mu \mathrm{L}$ do soro controle positivo, do soro controle negativo (animal de área não endêmica saudável) e das amostras de soros dos animais a serem testados, diluídas 1:400 em PBS contendo 0,05\% de tween 20 e $1 \%$ de BSA, foram adicionadas a cada poço e incubadas por três horas à temperatura ambiente. Após quatro lavagens com PBS-tween, foi adicionado à placa $100 \mu \mathrm{L}$ de anticorpo anti-IgG de cão, marcado com peroxidase previamente titulado. Após a incubação por uma hora em temperatura ambiente, a placa foi novamente lavada quatro vezes com PBS-tween e adicionou-se $100 \mu \mathrm{L}$ de uma solução contendo substrato OPD $(0,4 \mathrm{mg} / \mathrm{mL})$ em diluente apropriado. A reação foi interrompida adicionando-se a cada poço $50 \mu \mathrm{L}$ de $\mathrm{H}_{2} \mathrm{SO}_{4} 1 \mathrm{M}$ e a densidade óptica (D.O.) avaliada a 492nm, utilizando o leitor de ELISA (Labsystems Multiskan EX). Os resultados foram expressos pela média da densidade óptica obtida dos soros em duplicata. Realizou-se a determinação do ponto de corte da técnica de ELISA para a espécie com soros de cães sadios, provenientes de área não endêmica para LV. Foram considerados positivos ou reagentes aqueles que apresentaram valores superiores ao cut off 
encontrado, através da leitura no espectrofotômetro, considerando-se aqueles em que se evidenciaram valores de densidade óptica iguais ou superiores a média somada de três desvios-padrões do resultado dos soros controle negativo (BRASIL, 2006).

Já a RIFI foi realizada de acordo com Silva et al. (2009), sendo que as amostras foram testadas por método in house com antígeno obtido a partir de promastigotas de Leishmania infantum (syn. Chagasi). Diluições seriadas do soro dos animais foram incubadas em câmara úmida a $37^{\circ} \mathrm{C}$, por 30 minutos, em lâminas próprias contendo antígenos específicos para imunofluorescência. Foram, então, lavadas em tampão PBS $0.01 \mathrm{M} \mathrm{pH} 7.4$ e submetidas à incubação continuada utilizando-se anticorpo anti-IgG de cão, marcado com fluoresceína, por 30 minutos, em câmara úmida, a $37^{\circ} \mathrm{C}$. Finalmente, após nova lavagem em tampão PBS 0.01M pH 7.4, as lâminas foram montadas em glicerina tamponada com carbonato-bicarbonato $\mathrm{pH} \mathrm{9,0} \mathrm{e} \mathrm{observadas} \mathrm{em}$ microscópio de fluorescência (Olympus CH-2-BR). Soros caninos sabidamente positivos ou negativos foram utilizados, respectivamente, como controles positivos ou negativos da reação. Neste método, consideraram-se positivas as reações fluorescentes em soros com diluições iguais ou superiores a 1:40, conforme apregoado pelo Ministério da Saúde brasileiro (BRASIL, 2006).

\section{Diagnóstico parasitológico}

Amostras de linfonodos (pré-escapular e/ou poplíteo) e de medula óssea foram obtidas por citologia aspirativa por agulha fina (COWELL; TYLER, 1989). O procedimento de punção aspirativa de linfonodos foi realizado em 16 $(44,4 \%)$ animais da amostragem, qual seja aqueles que apresentavam linfoadenopatia. Em seis $(16,7 \%)$ dos casos, foi executada a citologia de medula óssea. Os esfregaços, do material assim colhido, foram estendidos em lâminas, corados pelo corante hematológico (Diff Quick - Panótico Rápido ${ }^{\circledR}$ Laborclin, São Paulo, Brasil) e examinados em microscópio óptico, com objetiva de 100, em imersão. Foi pesquisada e investigada a eventual presença de formas amastigotas livres ou no interior de macrófagos.

As amostras de tecido cutâneo, com lesões tegumentares características, foram biopsiadas com o auxílio de "punch" com tamanhos variados (dois, quatro ou seis milímetros). Os fragmentos foram fixados em formalina tamponada a 10\%. As amostras foram submetidas aos procedimentos de rotina histopatológica e uma vez estabelecido o diagnóstico presuntivo ou conclusivo da protozoose, os cortes histológicos foram processados pela técnica de imuno-histoquímica, de acordo com Moreira et al. (2007). Os cortes histológicos foram desparafinizados utilizando banho de xilol quente $\left(60^{\circ} \mathrm{C}\right)$ por 15 minutos e, posteriormente, banho de xilol frio por 15 minutos sendo, em seguida, hidratado, imergindo-o em álcool absoluto em dois banhos de cinco minutos, seguidos de banhos sucessivos de três minutos em álcool a 70\%, 50\% e $30 \%$, seguidos de um enxágue em água corrente e água destilada. Após, seguiu-se a recuperação antigênica em solução de ácido cítrico $10 \mathrm{mM} \mathrm{pH}$ 6,0 em banho Maria a $96-98^{\circ} \mathrm{C}$ por 30 minutos, esperando os cortes esfriarem para seguir a reação. Posteriormente, foi realizado o bloqueio da peroxidase endógena com seis banhos de 10 minutos com $\mathrm{H}_{2} \mathrm{O}_{2} 20$ volumes, descartando-se a água oxigenada e colocando-se em água corrente por 2 minutos, água destilada e dois banhos de cinco minutos em solução PBS $0,15 \mathrm{M} \mathrm{pH} 7,2$. Em seguida, fez-se o bloqueio de reação inespecífica com solução a $10 \%$ de leite desnatado em água destilada, durante 20 minutos, à temperatura ambiente. Após, os cortes foram incubados com os anticorpos primários diluídos em PBS $0,15 \mathrm{M} \mathrm{pH} 7,2$, acrescido de $1 \%$ de albumina bovina durante a noite a $4^{\circ} \mathrm{C}$. Após a lavagem dos cortes com STF $0,15 \mathrm{M}$ pH 7,2, em três banhos de cinco minutos, eles foram incubados com o anticorpo secundário (kit LSAB DAKO) durante 45 minutos à temperatura ambiente e, em seguida, com solução de estreptavidina- 
peroxidase (kit LSAB - DAKO), durante 30 minutos à temperatura ambiente. Seguindo-se nova lavagem com STF $0,15 \mathrm{M}$ pH 7,2, em três banhos de cinco minutos, a reação foi revelada com o substrato, uma solução de diaminobenzidina (DAB) $0,06 \mathrm{mg} / 100 \mathrm{~mL}$ de PBS, acrescida de $1 \mathrm{~mL}$ de peróxido de hidrogênio 20 volumes, por cinco minutos a temperatura ambiente, sendo a reação interrompida com água destilada. Procedeu-se a contra-coloração imergindo em hematoxilina de Mayer, durante três a cinco minutos, seguida de lavagens com água corrente e destilada, desidratação dos cortes com duas imersões em álcool absoluto durante cinco minutos e clareamento com xilol em duas imersões de cinco minutos. As lâminas foram montadas com resina e a leitura foi realizada sob microscopia óptica com objetiva de 40X.

\section{Resultados e Discussão}

Dos animais incluídos, 20 (55,5\%) eram fêmeas e os $16(44,5 \%)$ remanescentes eram machos, não tendo sido constatada aparente predisposição sexual frente a infecção, o que confirma os relatos pretéritos dispostos na bibliografia (FERRER, 1992; NOLI, 1999; FEITOSA et al., 2000, MARCONDES, 2013).

No que tange à faixa etária, quando do diagnóstico, esta se situava entre sete e 113 meses, com média de 51,3 meses. Quanto à idade, três (8,3\%) tinham até 12 meses, $19(52,8 \%)$ animais entre 13 e 48 meses, 10 (27,8\%) animais situavamse na faixa dos 49 a 96 meses e, finalmente, quatro $(11,1 \%)$ cães tinham mais de 96 meses. Com relação à predisposição etária, a faixa de idade que concentrou a maioria dos casos $(52,8 \%)$ foi aquela dos 13 a 48 meses de vida, qual seja, de adultos jovens. Contrariamente aos dados compilados da bibliografia especializada (FERRER, 1992; NOLI, 1999; FEITOSA et al., 2000) houve evidente predisposição por uma determinada faixa etária.

No tocante à predisposição racial, constatou-se que $12(33,3 \%)$ não apresentavam precisa definição racial. Dentre os $24(66,7 \%)$ cães de raça definida, incluíam-se: cinco animais da raça Poodle $(20,8 \%)$, cinco Labradores $(20,8 \%)$, três Boxers $(12,5 \%)$, dois Chow-Chows (8,3\%), dois Dachshunds $(8,3 \%)$, e um $(4,2 \%)$, respectivamente, das raças Basset Hound, Dobermann, Fila Brasileiro, Husky Siberiano, Pit Bull, Staffordshire Bull Terrier e Weimaraner.

A despeito da afirmativa de outros autores (FERRER, 1992; NOLI, 1999; FEITOSA et al., 2000, MARCONDES, 2013) de inexistir nítida predisposição racial quanto ao acometimento da protozoose, por haver, na dependência da região (país, estado, município) consideráveis variações relativas à população de cães de raça definida ou indefinida, algumas hereditariamente resistentes, evidenciou-se, no presente levantamento, uma maior ocorrência dentre aqueles cães de raças definidas, mormente Poodles e Labradores. Inegavelmente pelos dados de registros de casos atendidos no Serviço de Dermatologia, ambas as raças incluemse dentre aquelas mais atendidas, fato este que pode justificar tal predominância rácica.

Corroborando dados compulsados da bibliografia especializada (CIARAMELLA et al., 1997, MILLER; GRIFFIN; CAMPBELL, 2013) pôde-se verificar que cerca de dois terços (66\%) da casuística compreendia animais de grande porte, quais sejam aqueles criados habitualmente no exterior das propriedades em função de sua aptidão como animais de guarda ou trabalho.

No atinente ao local de aquisição do cão (provável local de nascimento ou de origem) incluíam-se municípios brasileiros ou países estrangeiros, tais como: no Estado de São Paulo: Araçatuba $(\mathrm{n}=3)$, Bauru $(\mathrm{n}=1)$, Campinas $(\mathrm{n}=1)$, Campo Limpo Paulista $(\mathrm{n}=1)$, Cotia $(\mathrm{n}=5), \mathrm{Embu}$ $(\mathrm{n}=4)$, Holambra $(\mathrm{n}=1)$, Ilha Bela $(\mathrm{n}=1)$, Mogi das Cruzes ( $\mathrm{n}=1)$, São Paulo/Capital $(\mathrm{n}=11)$, São Roque $(\mathrm{n}=1)$, Sorocaba $(\mathrm{n}=1)$, Ubatuba $(\mathrm{n}=1)$, Uberaba $(n=1)$. Porvieram, ainda, de Minas Gerais: Belo Horizonte $(n=2)$ e de Portugal com um caso. 
Quanto aos locais de residência ou de criação dos cães leishmanióticos quando trazidos para consulta, estes não eram, necessariamente os mesmos de origem. Dentre estes se incluíram: São Paulo/ Capital ( $=19)$, Embu $(n=4)$, Barueri $(n=1)$, Belo Horizonte $(\mathrm{n}=1)$, Birigui $(\mathrm{n}=1)$, Carapicuíba $(\mathrm{n}=$ 1), Cotia ( $n=3)$, Ilha Bela $(n=1)$, Mogi das Cruzes $(\mathrm{n}=1)$, Osasco $(\mathrm{n}=1)$, Paraty $(\mathrm{n}=1)$, Registro $(\mathrm{n}=$ 1), São Roque $(\mathrm{n}=1)$.

Caracterizando os animais, segundo o local aonde foram adquiridos ou de onde provieram, constatouse que seis $(16,67 \%)$ deles provinham de localidades descritas como "de transmissão canina e humana", ou seja, três cães originavam-se de Araçatuba (São Paulo), dois de Belo Horizonte (Minas Gerais) e um de Bauru (São Paulo); nove outros cães, sendo cinco $(13,9 \%)$ do município de Cotia e quatro $(11,1 \%)$ de Embu eram provenientes de municípios paulistas cuja caracterização epidemiológica é "de foco com transmissão canina". Os demais 21 cães procediam de cidades paulistas consideradas não endêmicas ou sob investigação. Vale ressaltar, ainda, que um dos cães era proveniente de outro país, no caso, Portugal, país este em que a leishmaniose canina é considerada endêmica (WHO, 1990).

Vinte e quatro $(66,6 \%)$ animais da amostragem considerada haviam sido deslocados a outros municípios ou estados da federação, por breves (menos de sete dias) ou longos períodos (semanas ou meses), preteritamente às manifestações dos sintomas da doença. Os locais de deslocamento referidos incluíram os Estados do Maranhão, Minas Gerais (Belo Horizonte e São Lourenço), Paraná (Umuarama), Rio de Janeiro (Paraty), São Paulo (Araçatuba, Birigui, Caraguatatuba, Cotia, Embu, Embu-Guaçu, Eldorado, Guarujá, Ilha Bela, Itapecerica da Serra, Peruíbe, Presidente Prudente, São Paulo e São Roque).

Vale lembrar que os municípios de Ilha Bela, Ubatuba, Caraguatatuba, Paraty e Umuarama são locais de casos notificados especialmente de leishmaniose tegumentar, sendo que alguns caninos da amostragem ali foram adquiridos. Quanto ao local de criação observou-se que somente dois cães residiam, respectivamente, em Ilha Bela e Paraty, municípios em que a leishmaniose tegumentar é sabidamente ocorrente. Quanto ao local onde os animais se deslocaram, a maioria esteve tanto em áreas com foco de transmissão canina e/ou humana de leishmaniose visceral (como Araçatuba, Birigui, Belo Horizonte, Cotia, Embu, Maranhão e Presidente Prudente), como também em regiões onde a leishmaniose tegumentar é presente, não se obtendo uma particular caracterização do local de infecção, uma vez que todos os cães deslocados haviam transitado por alguma dessas áreas.

Diante dos dados coligidos permite-se pressupor que a leishmaniose pode ter sido adquirida, principalmente, dos locais (municípios ou estados) onde há focos descritos da doença, bem como de presença do vetor. Dos casos ora evidenciados, caracterizaram-se deslocamentos a municípios ou estados que circundam ou fazem fronteira com o Estado de São Paulo, excetuando apenas um cão que se deslocou do estado do Maranhão. Esta dispersão pode propiciar elementos que justificam a disseminação da zoonose em locais considerados como alóctones, ao menos em passado recente.

Segundo a classificação do quadro sintomatológico (sintomáticos, oligossintomáticos e assintomáticos), de acordo com Mancianti et al. (1988), observou-se que $17(47,2 \%)$ cães eram sintomáticos, $18(50 \%)$ oligossintomáticos e, somente um $(2,8 \%)$, assintomático. Em função da detalhada anamnese executada em que, por muitas vezes, com a singela indagação da origem ou de eventuais deslocamentos do animal, pôde-se aventar uma possível infecção ou pressupor a vigência da enfermidade mesmo com sintomas vagos e pouco característicos.

As lesões tegumentares ou fanéricas evidenciadas nos 35 cães sintomáticos e/ou oligossintomáticos encontram-se apresentadas na figura 1. As manifestações evidenciadas 
corroboraram aquelas descritas de há muito na bibliografia (FERRER, 1992; CIARAMELLA et al., 1997; SLAPPENDEL; FERRER, 1998; FERRER, 1999; NOLI, 1999; FEITOSA et al., 2000). É comum, tal como apresentado por 16 desses cães $(45,7 \%)$, a observação de áreas de rarefação pilosa e/ou alopecia, associadas ou não à ocorrência de erosões ou ulcerações (SLAPPENDEL, 1988; FEITOSA et al., 2000). Este acometimento pode ser explicado pela ação direta da Leishmania por sobre o folículo piloso ou por um distúrbio do metabolismo do ácido pantotênico, decorrente de graves alterações hepáticas ou, ainda, por deposição de imunocomplexos na membrana basal do tecido tegumentar. Em locais correspondentes aos calos de apoio é habitual a evidenciação de áreas de hiperqueratose e lignificação evoluindo para fissuras ou ulcerações. Estas alterações podem estar relacionadas a uma ação direta do parasita ou à vasculite necrotizante decorrente da deposição de imunocomplexos (CIARAMELLA et al., 1997).

Figura 1. Distribuição (\%) das alterações cutâneas ou fanéricas de 35 cães acometidos por leishmaniose, atendidos nos Serviços de Dermatologia e de Clínica Médica de cães e gatos do HOVET da FMVZ-USP (1997-2007). São Paulo (2012).

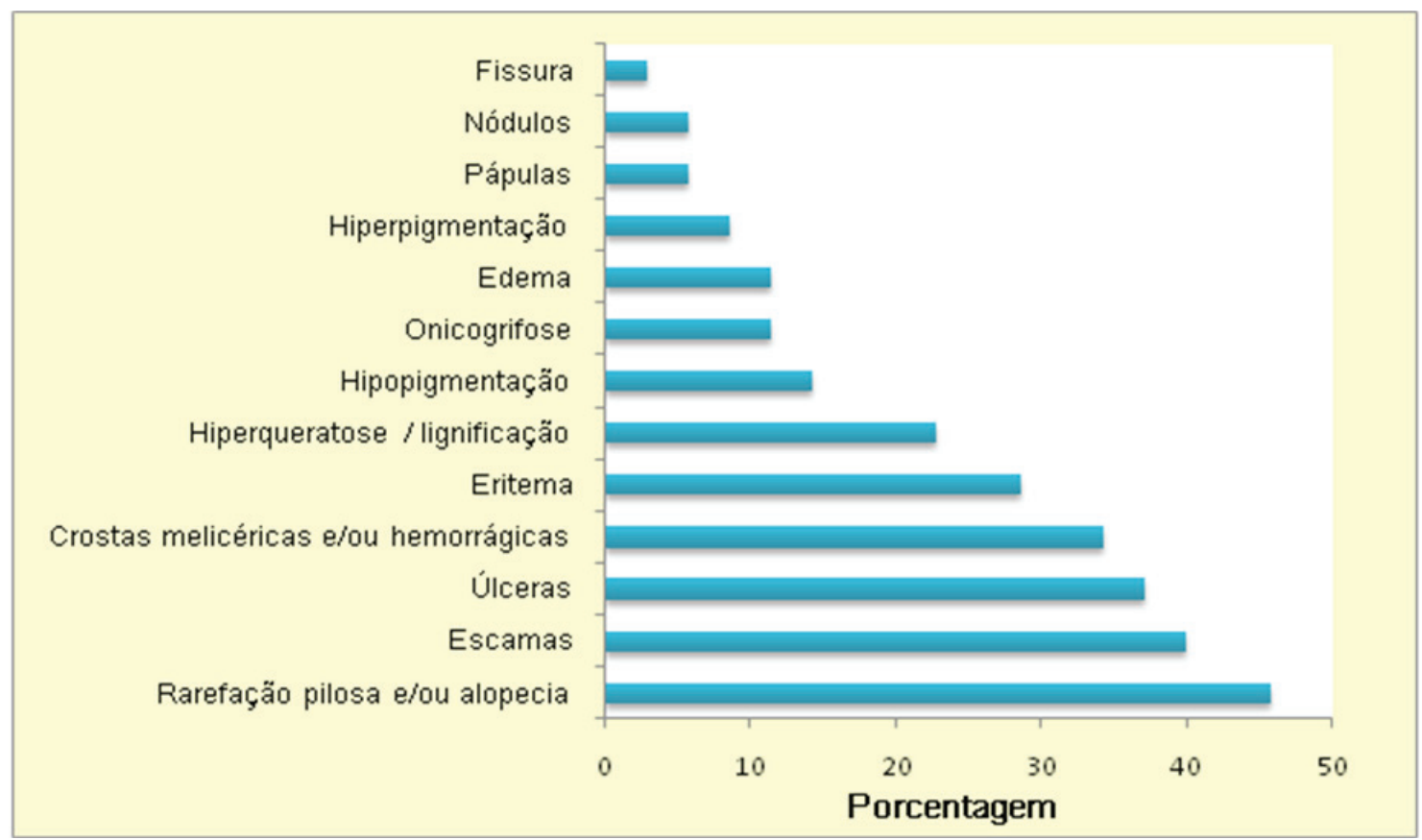

Fonte: Elaboração dos autores.

Dentre os oito (22,2\%) cães acometidos somente por lesões cutâneas, todos se apresentavam como oligossintomáticos. Somente um cão era totalmente assintomático, não apresentando alterações quer sistêmica quer dermatopática. Segundo Slappendel e Ferrer (1998) e (MILLER; GRIFFIN; CAMPBELL, 2013), as alterações cutâneas são bem frequentes em cães com leishmaniose e podem ser tanto localizadas como disseminadas, ocorrendo, na dependência do estado imunitário ou de vigência de outras enfermidades.

Considerando-se a distribuição topográfica de assestamento lesional, puderam-se verificar, em ordem decrescente de ocorrência, que as regiões 
cefálica, de articulações úmero-rádio-ulnares, de membros pélvicos e torácicos (incluindo patas e coxins) e região abdominal ventral foram as mais acometidas, sendo que, na região cefálica, também em ordem decrescente, os locais mais comprometidos foram o plano nasal (34,3\%), os pavilhões auriculares $(31,4 \%)$ e as regiões periocular $(22,8 \%)$ e perilabial $(17,1 \%)$. A predileção pelo assestamento lesional cefálico reflete provavelmente os hábitos fastidiosos dos flebotomíneos que habitualmente fazem seu repasto sanguíneo neste segmento corpóreo, atraídos que são pelo gás carbônico expelido pela expiração.

Quando se consideram as alterações tegumentares há que se diferenciar as lesões localizadas daquelas generalizadas. As primeiras caracterizam a "leishmaniose cutânea localizada" correspondendo ao ponto de inoculação do agente pela picada do díptero. Tais lesões nódulo-eritematosas ou erodoulcerativas, assimétricas (cancro de inoculação ou leishmanioma) não foram evidenciadas em boa parte da casuística considerada, afora em dois dos cães.

Uma vez vencida a fase inicial ou de estrita localização topográfica produz-se a disseminação visceral generalizada. Tal quadro acomete entre 40 e 70\% dos cães enfermos (CIARAMELLA et al., 1997; VILAGRAN, 1997; BLAVIER et al., 2001) caracterizando-se por ser apruriginoso, tal como manifestado por $64 \%$ da casuística considerada. As lesões tegumentares ou fanéricas presentes em 97\% destes casos coincidiam, tanto em termos de magnitude de percentual como de tipos e topografia lesional, com o referido na bibliografia compulsada (CIARAMELLA et al., 1997; VILAGRAN, 1997; BLAVIER et al., 2001; GROSS et al., 2005; BANETH, 2006).

O acometimento sistêmico foi detectado em 27 (75\%) cães do total da amostragem, sendo que a distribuição e o tipo das alterações detectadas encontram-se dispostas na figura 2. Quanto à linfoadenomegalia observada, achado de magnitude semelhante foi relatado por Feitosa et al. (2000), que enfocaram o habitual comprometimento deste órgão, ao estudar os aspectos clínicos de leishmaniose canina, no município de Araçatuba (São Paulo). Já, a esplenomegalia não foi um achado clínico comum neste estudo, sendo que, segundo a bibliografia compulsada, muitas vezes esta apresentação pode ser pré-clínica necessitando de exames de imagem, tais como os radiográfico e ultrassonográfico, para sua detecção. Contudo, a evidência de esplenomegalia em percentil relativamente alto já foi reportada por Slappendel (1988) e Ciaramella et al. (1997).

A pirexia é, segundo Feitosa et al. (2000), achado clínico comum, com valores de temperatura interna variando entre $40,5^{\circ} \mathrm{C}$ e $41^{\circ} \mathrm{C}$. A perda de peso, evidenciada em 29,7\% dos cães estudados, está frequentemente associada ao envolvimento visceral, podendo ocorrer mesmo em cães normoréticos (FEITOSA et al., 2000). Nestes cães, houve envolvimento do sistema hepático e/ou intestinal em oito animais.

Há controvérsias sobre a ocorrência de lesão hepática em cães com leishmaniose visceral; alguns autores relatam que o envolvimento hepático ocorre apenas em uma pequena porcentagem de cães (FERRER, 1992; CIARAMELLA et al., 1997), outros reportam-na como sendo mais comum (KONTOS; KOUTINAS, 1993). Sabe-se que os parasitas se multiplicam nos macrófagos hepáticos. Há evolução para hepatite ativa crônica, que se manifesta, clinicamente, por êmese, poliúria, polidipsia, anorexia e emagrecimento, podendo-se, muitas vezes se evidenciar hepatomegalia, tal como o observado em 29,7\% desta casuística (FERRER, 1992; KONTOS; KOUTINAS, 1993; NOLI, 1999, MILLER; GRIFFIN; CAMPBELL, 2013).

Os quadros de diarréia crônica são devidos à presença de ulcerações nas mucosas gástrica e/ou intestinal, resultando em fezes aquosas acompanhadas de hematoquezia ou melena, associados ou não a êmese (CIARAMELLA; CORONA, 2003). 
Figura 2. Distribuição (\%), segundo o tipo de alteração sistêmica, de 27 cães acometidos por leishmaniose atendidos nos Serviços de Dermatologia e de Clínica Médica de cães e gatos do HOVET da FMVZ-USP (1997-2007). São Paulo (2012).

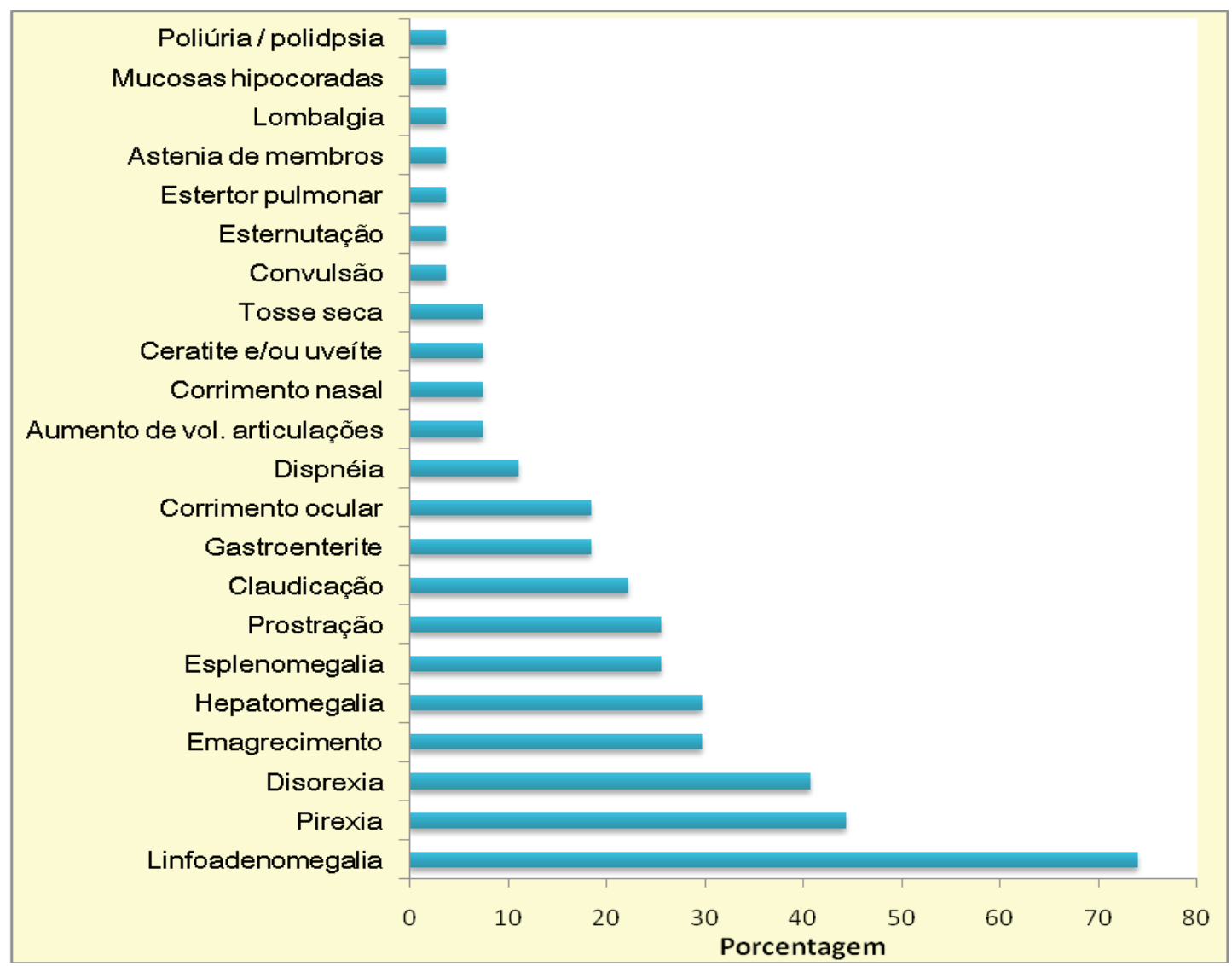

Fonte: Elaboração dos autores.

Dentre os sintomas neurológicos em casos de cães com leishmaniose, destacam-se os episódios convulsivos, tal como evidenciado em um dos cães, alterações em pares de nervos cranianos e das regiões vestibular e cerebelar. Tais manifestações neuropáticas podem ser decorrentes da deposição de imunocomplexos ou de vigência de infecções sediadas no sistema nervoso central (LIMA et al., 2003; MARCONDES, 2009).

Dos 36 animais da amostragem, seis $(16,6 \%)$ apresentavam outras enfermidades, quiçá decorrentes ou associadas à leishmaniose, sendo que destes, três $(50,0 \%)$ animais apresentavamse com sarna demodécica, dois $(33,3 \%)$ com urolitíase, sendo as alterações comprovadas pelos exames de ultrassonografia e de urina e, finalmente, um cão com erliquiose (16,7\%), diagnosticada pela identificação microscópica direta, em leucócitos de esfregaços sanguíneos, de mórulas de Ehrlichia sp. Estes diagnósticos foram estabelecidos no decorrer do seguimento clínicodermatológico, a contar do primo atendimento. Dois cães apresentavam antecedentes mórbidos, um deles de broncopneumonia e outro de pielonefrite, diagnosticados, respectivamente, há cerca de seis e 13 meses antes do primeiro atendimento no Serviço de Dermatologia. Nenhum animal apresentava antecedentes recentes, ou seja, há menos de três meses, a contar do primo atendimento, de utilização de medicação sistêmica e/ou tópica.

Com exceção do quadro vesical, confirmou-se a possibilidade de ocorrência de outras infecções e 
infestações eventualmente associadas ao quadro de leishmaniose (CIARAMELLA et al., 1997). Tanto a sarna demodécica como a erliquiose podem tanto preceder como suceder a leishmaniose. Ambas podem, também, agravar ou serem agravadas pela imunossupressão que habitualmente provém da presença de linfócitos $\mathrm{T}$ (supressores ou auxiliares) e da ação de algumas das linfocinas, na vigência do quadro protozoótico.

Correlacionando-se a enfermidade aos achados laboratoriais, constatou-se que 13 animais $(36,1 \%)$ não apresentaram quaisquer alterações hematológicas e/ou bioquímicas séricas e/ou urinárias. Em 23 (63,9\%) deles verificaram-se achados, tais como: hiperproteinemia (56,5\%), hipoalbuminemia (52,1\%), anemia (34,8\%), trombocitopenia $(34,8 \%)$, hiperfosfatasemia alcalina $(17,4 \%)$, proteinúria $(8,7 \%)$, cristalúria $(8,7 \%)$ e, por fim, em $4,3 \%$ dos casos foi observado aumento de atividade sérica da alanina aminotransferase, leucocitose e linfopenia absolutas.

A alteração do perfil protéico é referida em trabalhos de autores estrangeiros (BANETH, 2006) em percentis que oscilam entre 60 e $68 \%$, no que tange à hiperproteinemia. Na leishmaniose visceral canina, apesar dos níveis de proteínas totais estarem aumentados, ocorre uma disproteinemia. $\mathrm{Na}$ eletroforese de proteínas séricas observa-se uma inversão e diminuição da relação albumina/ globulina, em função do aumento da fração gama, o que caracteriza uma hipergamaglobulinemia, com diminuição da albumina em número representativo de casos (GENARO, 1993; CIARAMELLA; CORONA, 2003).

Destaque-se que níveis globulinêmicos elevados, em cães, de regiões endêmicas ou que tenham sido deslocados para tais locais, sem um claro fator causal, deve incitar a investigação soro e parasitológica (BANETH, 2006).

Outros achados laboratoriais referiam-se aos exames hematológicos alterados. Segundo alguns autores, de 57 a 94,2\% dos animais com leishmaniose visceral podem apresentar quadro de anemia normocítica e normocrômica (KONTOS; KOUTINAS, 1993; CIARAMELLA; CORONA, 2003; IKEDA et al., 2003; BANETH, 2006). A sua patogênese não é totalmente conhecida e acreditase que mais de um fator esteja envolvido, como: sequestro esplênico de hemácias, diminuição da produção medular, falência renal crônica, hemorragias entéricas e renais, hemólise e daqueles decorrentes de mecanismos de imunomediação (KONTOS; KOUTINAS, 1993; VILAGRAN, 1997; CIARAMELLA; CORONA, 2003, IKEDA et al., 2003).

Com relação às alterações plaquetárias, alguns autores relatam que a contagem de trombócitos pode estar normal (MORENO; LUCENA; GINEL, 1998), enquanto que outros reportam a ocorrência de trombocitopenia (SLAPPENDEL; FERRER, 1998; CIARAMELLA; CORONA, 2003). Segundo Baneth (2006) a trombocitopenia não é um achado consistente na evolução da leishmaniose visceral canina. Suas possíveis causas são supressão de sua produção em medula óssea, sequestro esplênico, presença de imunocomplexos circulantes e autoanticorpos (KONTOS; KOUTINAS, 1993; SLAPPENDEL; FERRER, 1998).

Já, os quadros de leucocitose por neutrofilia, quando presentes, segundo a bibliografia consultada, estão normalmente associados a quadro de infecção bacteriana secundária. Alguns autores descrevem a presença de leucocitose associada à neutrofilia (ANOSA; IDOWU, 1993), enquanto outros relatam a ocorrência de leucopenia (ABRANCHES et al., 1991) em cães acometidos pela leishmaniose. As alterações quantitativas linfocitárias são pouco frequentes, havendo muitas discordâncias nos dados bibliográficos quanto à ocorrência de linfocitose ou de linfopenia. Segundo Bourdoiseau et al. (1997), os animais soropositivos em bom estado clínico apresentam linfocitose, enquanto aqueles com quadro clínico grave manifestam linfopenia. Já, Ikeda et al. (2003), observaram tanto linfocitose quanto linfopenia em 191 cães, naturalmente 
infectados com Leishmania chagasi, investigados no município de Araçatuba (São Paulo).

A principal alteração encontrada, no exame de urina, foi a proteinúria, sendo que perda protéica é citada por alguns autores (KONTOS; KOUTINAS, 1993; SLAPPENDEL; FERRER, 1998). Vilagran (1997) afirmou que na leishmaniose visceral canina do Velho Mundo, os achados laboratoriais tal como proteinúria (com ou sem hematúria), associados às disproteinemias séricas, às anemias e a níveis elevados de uréia constituem-se em dados de valor orientativo para a diagnose da enfermidade. As determinações da concentração sérica de uréia e creatinina não propiciam elementos para o diagnóstico quando da ocorrência de lesões renais iniciais, desta forma, segundo Lopez et al. (1996), o exame de urina é um dos primeiros exames de função renal que dever ser solicitado.

Dos quatro cães com leishmaniose que apresentaram hiperfosfatasemia alcalina, somente dois apresentavam hepatomegalia. Em relação ao aumento de atividade da enzima ALT, o animal acometido também não apresentava visceromegalia na avaliação física. Isto condiz com os relatos brasileiros de Genaro (1993) e Feitosa et al. (2000) que asseguraram que nem todos os animais que apresentam alterações de enzimas hepáticas apresentam hepatomegalia.

Por se tratar de levantamento retrospectivo de casuística, não foi realizado um delineamento experimental previamente ao início da realização do estudo, portanto, nem todos os animais foram avaliados pelas mesmas técnicas diagnósticas. Entre os 36 animais leishmanióticos, evidenciaramse, pelas técnicas sorológicas, 34/35 (97,1\%) como positivos pelo método de ELISA e 18/21 (85,7\%) pela RIFI. Quanto aos métodos parasitológicos empregados, em 4/13 (30,8\%) cães detectou-se o agente parasitário por exame histopatológico e em outros três $(23,0 \%)$ cães observou-se padrão histológico "sugestivo" de leishmaniose; em 7/12 (92,3\%) evidenciou-se imunomarcação, pela técnica de imuno-histoquímica, representativa de positividade para a enfermidade, bem como houve resultado positivo, por exame parasitológico direto de linfonodo, em 6/16 (37,5\%) casos, e por punção aspirativa de medula óssea, em $4 / 6$ cães $(66,7 \%)$.

Os resultados dos exames subsidiários executados e sua correlação com o agrupamento relativo ao quadro sintomatológico (assintomático, oligo e sintomático) estão dispostos na tabela 1 . Daqueles animais em que fora realizada a sorologia pelo método de ELISA, verificou-se, entre os oligossintomáticos, positividade em 94,4\% deles e, no grupo dos sintomáticos, a totalidade dos animais mostrou-se soropositivo, indicando uma resposta imune humoral com produção de imunoglobulinas anti-Leishmania pouco mais frequente no grupo sintomático em relação aos oligossintomáticos. Estes animais provavelmente manifestavam resposta $\mathrm{Th} 2$ mais efetiva que, além de favorecer a produção de anticorpos, permitiria o desenvolvimento da doença ativa com evidência da sintomatologia.

Pela RIFI, o grupo sintomático apresentou percentual maior de soropositivos comparado àqueles do grupo oligossintomático. Houve soronegatividade $(33,3 \%)$ à RIFI somente dentre os animais oligossintomáticos. No soro dos 21 animais em estudo em que se realizou a RIFI, houve maior percentagem de positividade em animais sintomáticos (100\%) relativamente aos oligossintomáticos $(66,7 \%)$. Nas leituras da RIFI, os títulos séricos dos 18 cães reagentes foram iguais ou maiores a 160, ou seja, evidentemente positivos. Pela bibliografia compulsada, alguns autores consideram que o melhor nível de corte para o teste RIFI, é de 1:80 (MANCIANTI et al., 1988; CABRERA, 1999). Já Neogoy et al. (1992), observaram que a diluição 1:160 é aquela que apresenta $100 \%$ de especificidade, o que significa que todos os verdadeiros positivos podem ser identificados a partir de tais títulos, impedindo dessa forma, que animais não infectados sejam eliminados. O Ministério da Saúde brasileiro, no entanto, caracteriza como sororreagentes aqueles 
animais com títulos iguais ou superiores a 40. A RIFI tem sido a técnica sorológica mais utilizada para o diagnóstico da leishmaniose canina, particularmente em inquéritos epidemiológicos (BRASIL, 2006), apresentando sensibilidade que varia de 90 a $100 \%$ e especificidade da ordem de 80 a 100\% (ALVES; BEVILACQUA, 2004). Constitui-se em técnica laboriosa e que requer bom treinamento do observador para a interpretação dos resultados, pois o limite entre o que se considera reações "positivas" ou "negativas" é muito sutil e, por vezes, até subjetivo.

Correlacionando-se os resultados considerados, comparando-se os métodos de ELISA e RIFI entre si, observou-se que ambos os métodos apresentaram evidente positividade no grupo de cães em que se realizou os dois exames. No grupo de cães oligossintomáticos, porém, a RIFI apresentou percentagem $(33,3 \%)$ significantemente maior de resultados negativos quando comparados ao ELISA (5,6\%). Segundo os resultados de estudos que compararam o teste ELISA e a RIFI, por meio da determinação do coeficiente Kappa, observa-se uma concordância considerada como boa entre a RIFI e o teste ELISA (ZANETTE, 2006). Segundo alguns outros autores, o método de ELISA tem mostrado maior sensibilidade e especificidade quando comparado à RIFI (MANCIANTI et al., 1995). Ainda, de acordo com Almeida et al. (2005), os exames sorológicos (ELISA e RIFI), mormente quando associados, são essenciais para confirmar a suspeição de leishmaniose canina.

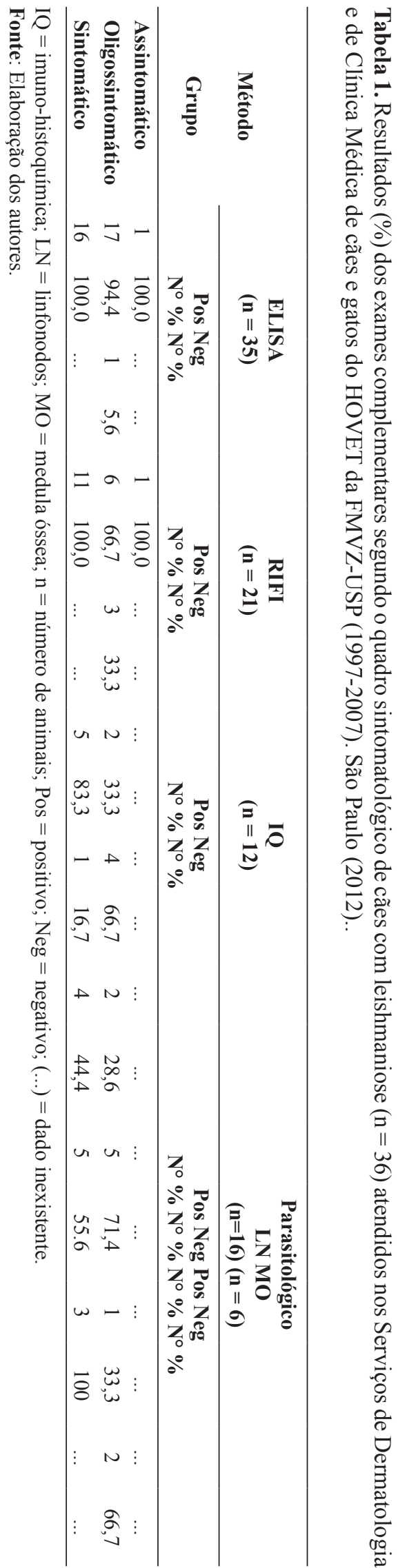


Os resultados do exame parasitológico executado a partir de material colhido, por citologia aspirativa de linfonodos superficiais (pré escapulares e/ou poplíteos) de 16 animais, propiciou a evidenciação do agente em seis $(37,5 \%)$ deles. Quando se compara os resultados entre os oligo e sintomáticos pôde-se verificar a presença do agente em, respectivamente, 28,6 e 45,4\% dos cães. É imprescindível destacar que a positividade se altera com a habilidade daquele que biopsia os linfonodos, com a magnitude do enfartamento linfonodal, com o treinamento daquele que examina (WOLSCHRIJN et al., 1996) e, ainda, com a eventual interposição de tratamento pretérito, com derivadores metabólicos (alopurinol), fungistáticos (azólicos), parasiticidas (antimoniais), dentre outros. Nenhum dos animais, em que se observou a ausência de parasitas, houvera sido ou estava sob terapia quando da colheita. Não se pôde, no entanto, nesta casuística descartar a hipótese de que, nos grupos sintomático e oligossintomático, a resposta imune desencadeada tenha propiciado uma maior destruição de formas amastigotas, dificultando sua visualização no exame parasitológico (PINELLI; RUTTEN, RUITEMBERG, 1999). Ainda, em alguns pacientes a visualização de parasitas é muito laboriosa e os resultados negativos não são incomuns, especialmente nos casos crônicos (SLAPPENDEL, 1988; IKEDA-GARCIA; FEITOSA, 2006).

Já, o exame parasitológico de medula óssea, realizado em seis cães, permitiu evidenciar percentagem plena de positividade (100\%) nos animais do grupo sintomático. Segundo a bibliografia, acredita-se que a quantidade de formas amastigotas de Leishmania seja maior na medula óssea e no baço, relativamente aos linfonodos. Por esse motivo considera-se, também, que o exame parasitológico por punção aspirativa esplênica e de medula óssea seja superior quando comparada àquela de linfonodos (FERRER, 1992). De acordo com Manolis et al. (2005), a sensibilidade tanto do exame parasitológico, por biópsia aspirativa de linfonodos como de medula óssea, está diretamente relacionada à intensidade da sintomatologia. Nos grupos estudados, mesmo que realizado em tão somente seis animais, observou-se maior percentagem no grupo de animais sintomáticos.

Quanto ao exame parasitológico de linfonodos e/ou de medula óssea, este é um dos métodos tradicionais e, supostamente, mais simples dentre os empregados para o diagnóstico da leishmaniose canina, no qual se busca o parasito na sua forma amastigosta. A especificidade deste método é de cerca de $100 \%$, embora a sensibilidade seja estimada como sendo de no máximo $80 \%$ em cães sintomáticos e em menores percentis nos cães assintomáticos (SLAPPENDEL; FERRER, 1998). A sensibilidade deste método varia de acordo com os autores, como sendo de menos de $30 \%$ ou entre 30 a $85 \%$ para o exame parasitológico, quando realizado a partir de material colhido dos linfonodos (FERRER, 1999; KOUTINAS et al., 2001). Quando da execução do exame parasitológico da combinação de linfonodos superficiais e de medula óssea, a sensibilidade alcança patamares de 71 a 90\% (KOUTINAS et al., 2001).

Quanto aos achados histopatológicos de material cutâneo, estes podem ser inespecíficos e se caracterizam por uma reação inflamatória crônica, por vezes granulomatosa, com presença de infiltrado linfohistioplasmocitário, alterações estas, comuns a várias outras dermatopatias. O exame histopatológico pode ser inconclusivo, principalmente quando houver uma baixa densidade, a nível cutâneo, das formas amastigotas de Leishmania sp (FERRER, 1999), necessitando, muitas vezes, recorrer-se à técnica de imunohistoquímica para corroborar o diagnóstico (FERRER et al., 1988a; BOURDOISEAU et al., 1997). Nos 13 cães em que foi realizado o exame histopatológico de tecido cutâneo lesado evidenciou-se o agente parasitário da Leishmania sp em 30,8\%. Nestes, o quadro histológico fora descrito como apresentando "denso infiltrado linfoplasmocitário", estando infiltrado por macrófagos, 
cujos citoplasmas eram vacuolizados e continham, em seu interior, grande número de parasitos.

De acordo com Baneth (2006), é comum observar, em exames histológicos de pele, infiltrado plasmocitário difuso, associados à perifoliculite granulomatosa. Também, tem sido relatado que quadros histológicos tais como piogranuloma estéril ou a adenite sebácea granulomatosa podem estar sendo mimetizadas pelo quadro leishmaniótico (GROSS et al., 2005). No presente estudo, três cães apresentaram quadros histológicos distintos, condizentes, respectivamente, a lúpus eritematoso discóide, piogranuloma estéril e hemangioma ulcerado. Em 23\% dos cães da amostragem foi descrito quadro histológico "sugestivo" de leishmaniose, observando, histologicamente, uma "dermatite granulomatosa ulcerativa", estando associado à presença de macrófagos vacuolizados com estruturas em seu interior podendo corresponder, ou sugerir, serem formas amastigotas do parasito. Nos demais três cães constataram-se quadro histológico de "dermatite ulcerativa sem caráter específico". De acordo com Ferrer et al. (1988b) lesões ulceradas em cães com leishmaniose podem estar associadas a um número limitado de amastigotas em seu tecido de revestimento, tornando o exame histopatológico pouco sensível.

No tocante aos resultados do emprego de imunohistoquímica a partir de fragmentos emblocados, de pele lesada e biopsiada, proveniente de 12 cães, pôde-se identificar o protozooário em sete $(58,3 \%)$ deles. Ao se considerar a positividade frente ao agrupamento, segundo as manifestações sintomáticas, constatou-se que, respectivamente, em cinco $(83,3 \%)$ e dois $(33,3 \%)$, de sintomáticos e oligossintomáticos, houve imunomarcação. Estes percentis podem induzir a interpretações de que nos cães ditos sintomáticos há presença de maior número de formas do parasito. Tais resultados, mesmo considerando o número restrito de animais, apontam para a importância do uso desta técnica na rotina diagnóstica laboratorial. Segundo Ferrer (1999), o método ideal para o diagnóstico da leishmaniose canina seria aquele que apresente altos percentis de especificidade e de sensibilidade, que seja de baixo custo e de rápido resultado. Apesar da execução da imunoistoquímica dispender mais tempo e de não apresentar baixo custo para sua realização, tal técnica propicia valores elevados de sensibilidade e de especificidade (MOREIRA et al., 2007), principalmente em cães com flagrante quadro clínico, sistêmico e dermatológico (BOURDOISEAU et al., 1997).

Em contrapartida, segundo Tafuri et al. (2001) e Abranches, Campino e Santos-Gomes (1998), em cães leishmanióticos sintomáticos com intenso parasitismo em muitos órgãos internos, pode-se não evidenciar o parasita na pele, enquanto que em cães assintomáticos pode haver parasitismo tegumentar evidente. Os mecanismos pelos quais os parasitos se disseminam no tegumento dos cães acometidos pela leishmaniose ainda são obscuros e podem, provavelmente, estar relacionados a fatores imunogenéticos individuais dos hospedeiros e ao transcurso da doença (TRAVI et al., 2001). No presente levantamento não houve diferença percentual tão evidente entre cães positivos $(58,3 \%)$ e negativos $(41,7 \%)$.

Correlacionando os resultados obtidos pela técnica de imunoistoquímica com o exame parasitológico direto, dos sete animais em que ambas foram realizadas, observou-se resultados positivos pela imuno-histoquímica em quatro $(57,1 \%)$ dos casos, tendo, portanto, sido mais representativa quando comparada com o exame parasitológico direto, que apresentou positividade em três $(42,9 \%)$ dos animais avaliados. Em dois dos casos os resultados foram positivos por ambos os métodos, em outros dois animais houve positividade somente por imuno-histoquímica e, em um dos cães, o diagnóstico foi alcançado apenas pelo exame citológico. De acordo com tais resultados, pode-se sugerir que a imuno-histoquímica seria o exame mais significativo, comparativamente entre os dois métodos empregados, porém, uma maior amostragem de animais com realização de tais 
exames seria imprescindível para se concluir sobre a fidedignidade dos resultados ora apresentados.

A leishmaniose é uma zoonose de notificação compulsória, sendo que o diagnóstico etiológico deve ser executado de modo mais preciso possível, inclusive para evitar a adoção de medidas extremadas em animais hígidos erroneamente reputados como "infectados". Devido à variedade de sintomas da doença, o diagnóstico clínico da leishmaniose canina é difícil, sendo importante que se conheça profundamente o método diagnóstico utilizado, suas limitações e sua interpretação clínica. Além disso, em se considerando os dados ora apresentados, ressalta-se a necessidade de que os médicos veterinários e órgãos vinculados à saúde pública daqueles municípios considerados de "não transmissão" da enfermidade estejam atentos ao fato de que animais oriundos de localidades onde a leishmaniose é considerada endêmica possam ser deslocados livremente por outros locais e, portanto, servirem como fonte de infecção, sendo de suma importância a divulgação e a adoção, pelos agentes de saúde, das medidas preventivas para que a transmissão nas áreas indenes não ocorra.

\section{Observações}

Trabalho aprovado pela Comissão de Bioética da Faculdade de Medicina Veterinária e Zootecnia da Universidade de São Paulo sob o protocolo de $n^{\circ}$ $1204 / 2007$.

\section{Referências}

ABRANCHES, P.; CAMPINO, L.; SANTOS-GOMES, G. M. Leishmaniose canina: novos conceitos de epidemiologia e imunopatologia e seus reflexos no controle da leishmaniose visceral humana. Acta Médica Portuguesa, Lisboa, v. 11, n. 10, p. 871, 1998.

ABRANCHES, P.; SANTOS-GOMES, G.; RACHAMIM, N.; CAMPINO, L.; SCHNUR, L. F.; JAFFE, C. L. An experimental model for canine visceral leishmaniasis. Parasite Immunology, Oxford, v. 13, n. 5, p. 537-550, 1991.
ALMEIDA, M. A. O.; JERUSA, E. E. V.; SOUZAATTA, M. L. B.; ALVES, L. C.; BERNNE, M. E. A.; ATTA, A. M. Clinical and serological aspects of visceral leishmaniasis in Northeast Brazilian dogs naturally infected with Leishmania chagasi. Veterinary Parasitology, Amsterdam, v. 127, n. 3-4, p. 227-232, 2005.

ALVES, W. A.; BEVILACQUA, P. D. Reflexos sobre a qualidade do diagnóstico da leishmania visceral canina em inquéritos epidemiológicos: o caso da epidemia de Belo Horizonte, Minas Gerais, Brasil, 1993-1997. Caderno de Saúde Pública, Rio de Janeiro, v. 20, n. 1, p. 259-265, 2004.

ANOSA, V. O.; IDOWU, A. L. The clinicohaematological features and pathology of leishmaniasis in a dog in Nigeria. Zentralblatt Veterinarmedizin. Reithe B., Berlin, v. 30, n. 8, p. 600-608, 1983.

BADARÓ, R.; DUARTE, M. I. S. Leishmaniose visceral (Calazar). In: VERONESI, R.; FOCACCIA, R. Tratado de infectologia. São Paulo: Atheneu, 1996. p. 1234-1259.

BANETH, G. Leishmaniases. In: GREENE, C. E. (Ed.). Infectious diseases of the dog and cat. Georgia: Saunders Elsivier, 2006. p. 685-698.

BLAVIER, A.; KEROACK, S.; DENEROLLE, P.; GOY-THOLLOT, I.; CHABANNE, L.; CADORÉ, J. L.; BOURDOISEAU, G. Atypical forms of canine leishmaniasis. The Veterinary Journal, London, v. 162, n. 2, p. 108-120, 2001.

BOURDOISEAU, G.; BONNEFONT, C.; MAGNOL, J. P.; SAINT-ANDRÉ, I.; CHABANNE, L. Lymphocyte subset abnormalities in canine leishmaniasis. Veterinary Immunology and Immunopathology, Amsterdam, v. 56, n. 3-4, p. 345-351, 1997.

BRASIL. Ministério da Saúde. Secretaria de Vigilância em Saúde. Departamento de Vigilância Epidemiológica. Manual de vigilância e controle da leishmaniose visceral. Brasília: Ministério da Saúde, 2006. 120 p.

CABRERA, M. A. A. Ciclo enzoótico de transmissão da Leishmania (Leishmania chagasi) (Cunha \& Chagas 1937) no ecótopo peridoméstico em Barra de Guaratiba. Rio de Janeiro, RJ: estudo de possíveis variáveis preditoras. 1999. Tese (Mestrado em Saúde Pública) Fundação Oswaldo Cruz. Escola Nacional de Saúde Pública, Rio de Janeiro.

CIARAMELLA, P.; CORONA, M. Canine leishmaniasis: clinical and diagnostic aspects. Compendium on Continuing Education for the Practicing Veterinarian, Los Angeles, v. 25, n. 5, p. 358-368, 2003. 
CIARAMELLA, P.; OLIVA, G.; DE LUNA, R.; GRADONI, L.; AMBROSIO, R.; CORTESE, L.; SCALONE, A.; PERSECHINO, A. A retrospective clinical study of canine leishmaniasis in 150 dogs naturally infected by Leishmania infantum. Veterinary Record, London, v. 141, n. 21, p. 539-543, 1997.

COLOMBO, F. A.; ODORIZZI, R. M. F. N.; LAURENTI, M. D.; GALATI, E. A. B.; CANAVEZ, F.; PEREIRA-CHOCCOLA, V. L. Detection of Leishmania (Leishmania) infantum RNA in fleas and ticks collected from naturally infected dogs. Parasitology Research, Berlin, v. 109, n. 2, p. 267-74, 2011.

COWELL, R. L.; TYLER, R. D. Cytology of cutaneous lesions. Veterinary Clinics of North America: Small Animal Practice, Philadelphia, v. 19, n. 4, p. 769-794, 1989.

FEITOSA, M. M.; IKEDA, F. A.; LUVIZOTTO, M. C. R.; PERRI, S. H. V. Aspectos clínicos de cães com leishmaniose visceral no município de Araçatuba - São Paulo (Brasil). Revista Clínica Veterinária, São Paulo, v. 5, n. 28, p. 36-44, 2000.

FERRER, L. M. Leishmaniasis. In: KIRK, R. W.; BONAGURA, J. D. Current veterinary therapy: small animal practice. Phildelphia: W.B. Saunders, 1992. p. 266-270.

Clinical aspects of canine leishmaniasis. In: INTERNATIONAL CANINE LEISHMANIASIS FORUM, 1., 1999, Barcelona. Proceedings... Barcelona: Hoechst Roussel Vet, 1999, p. 6-10.

FERRER, L. M.; FONDEVILA, D.; MARCO, A.; PUMAROLA, M. Atypical nodular leishmaniasis in two dogs. Veterinary Record, London, v. 126, n. 4, p. 90, 1990.

FERRER, L. M.; RABANAL, R.; DOMINGO, M.; RAMOS, J. A.; FONDEVILA, D. Identification of Leishmania donovani amastigotas in canine tissues by immunoperoxidase staining. Research in Veterinary Science, Oxford, v. 44, n. 2, p. 194-196, 1988a.

FERRER, L. M.; RABANAL, R.; FONDEVILA, D.; RAMOS, J. A.; DOMINGO, M. Skin lesions in canine leishmaniasis. Journal of Small Animal Practice, Oxford, v. 29, p. 381-388, 1988 b.

GENARO, O. Leishmaniose canina experimental. 1993. Tese (Doutorado em Parasitologia) - Universidade Federal de Minas Gerais, Belo Horizonte.

GROSS, T.L.; IHRKE, P. J.; WALDER, E. J.;AFFOLTER, V. K. Infectious nodular and diffuse granulomatous and pyogranulomatous diseases of the dermis. In: GROSS,
T. L. (Ed.). Skin diseases of the dog and cat - clinical and histopathologic diagnosis. Rio de Janeiro: Blackwell Sciense, 2005. p. 272-319.

IKEDA, F. A.; CIARLINI, P. C.; FEITOSA, M. M.; GONÇALVES, M. E.; LUVIZOTTO, M. C. R.; LIMA, V. M. F. Perfil hematológico de cães naturalmente infectados por Leishmania chagasi no município de Araçatuba - SP: um estudo restrospectivo de 191 casos. Revista Clínica Veterinária, São Paulo, v. 8, n. 47, p. 4248, 2003.

IKEDA-GARCIA, F. A.; FEITOSA, M. M. Métodos de diagnóstico da leishmaniose visceral canina. Revista Clínica Veterinária, São Paulo, v. 11, n. 62, p. 32-38, 2006.

KONTOS, V. J.; KOUTINAS, A. F. Old world canine leishmaniasis. Compendium on Continuing Education for the Practicing Veterinarian, Los Angeles, v. 15, n. 7, p. 949-959, 1993.

KOUTINAS, A. F.; SARIDOMICHELAKIS, M. N.; MYLONAKIS, M. E.; LEONTIDES, L.; POLIZOPOULOU, Z.; BILLINS, C.; ARGYRIADIS, D.; DIAKOU, N.; PAPADOPOULOS, O. A randomised, blinded, placebo-controlled clinical Trial with allopurinol in canine leishmnaiosis. Veterinary Parasitology, Amsterdam, v. 98, n. 4, p. 247-261, 2001.

LIMA, V. M. F.; GONÇALVES, M. E.; IKEDA, F. A.; LUVIZOTTO, M. C. R.; FEITOSA, M. M. Antileishmania antibodies in cerebrospinal fluid dogs with visceral leishmaniasis. Brazilian Journal of Medical and Biological Research, Ribeirão Preto, v. 36, n. 4, p. 485489, 2003.

LOPEZ, R.; LUCENA, R.; NOVALES, M.; GINEL, P. J.; MARTIN, E.; MOLLEDA, M. Circulating immune complexes and renal function in canine leishmaniasis. Zentralblatt Veterinarmedizin. Reithe B., Berlin, v. 43, n. 8, p. 469-474, 1996.

MANCIANTI, F.; FALCONE, M. L.; GIANNELLI, C.; POLI, A. Comparison between an enzymelinked immunosorbent assay using a detergentesoluble Leishmania infantum antigen and indirect immunofluorescence for the diagnosis of canine leishmaniosis. Veterinary Parasitology, Amsterdam, v. 59, n. 1, p. 13-21, 1995.

MANCIANTI, F.; GRAMICCIA, M.; GRADONI, L.; PIERI, S. Studies on canine control. 1. Evolution of infection of different clinical forms of canine leishmaniasis following antimonial treatment. Transactions of the Royal Society of Tropical Medicine and Hygiene, London, v. 82, n. 4, p. 566-567, 1988. 
MANOLIS, M.; SARIDOMICHELAKIS, M. N.; MYOLONAKIS, M. E.; LEONTIDES, L. S.; BILLINIS, C.; DIAKOU, A.; KONTOS, V. I. Periodic administration of allopurinol is not effective for the prevention of canine leishmaniasis (Leishmania infantum) in the endemic areas. Veterinary Parasitology, Amsterdam, v. 130, n. 3-4, p. 199-205, 2005.

MARCONDES, M. Envolvimento do sistema nervoso central na leishmaniose visceral canina. 2009. Tese (Livre Docência) - Faculdade de Odontologia. Universidade Estadual Paulista Júlio de Mesquita Filho, Araçatuba.

Leishmaniose In: LARSSON, C. E.; LUCAS, R. Tratado de medicina externa. São Paulo: Interbook, 2013. p. 39-78.

MICHALSKY, E. M.; FORTES-DIAS, C. L.; PIMENTA, P. F. P.; SECUNDINO, N. F. C.; DIAS, E. S. Assessment of PCR in the detection of Leishmania spp in experimentally infected individual phlebotomine sandflies (Díptera: Psychodidae: Phlebotominae). Revista do Instituto de Medicina Tropical de São Paulo, São Paulo, v. 44, n. 5, p. 255-259, 2002.

MILLER, W. H.; GRIFFIN, C. E.; CAMPBELL, K. L. Viral, rickettsial and protozoal skin diseases. In: MULLER, W. H.; GRIFFIN, C. E. Kirks small animal dermatology. $7^{\text {th }}$ ed. Missouri: Elsevier, 2013. p. 354-357.

MOREIRA, M. A.; LUVIZOTTO, M. C.; GARCIA, J. F.; CORBETT, C. E.; LAURENTI, M. D. Comparison of parasitological, immunological and molecular methods of leishmaniasis in dogs with different clinical signs. Veterinary Parasitology, Amsterdam, v. 145, n. 3-4, p. 245-52, 2007.

MORENO, P.; LUCENA, R.; GINEL, P. J. Evaluation of primary haemostasis in canine lesihmaniasis. Veterinary Record, London, v. 142, n. 4, p. 81-83, 1998.

NEOGOY. A. B.; VOULDOUKIS, I.; SILVA, A. O.; TSELENTIS, Y.; LASCOMBE, J. C.; SEGALEN, T. Serodiagnosis and screening of canine visceral leishmaniasis Iná endemic área of Corsica: applicability of a direct agglutination test and immunoblot analysis. American Journal of the Tropical Medicine Hygiene, Baltimore, v. 47, n. 6, p. 772-777, 1992.

NOLI, C. Leishmaniosis canina. Waltham Focus, London, v. 9, n. 2, p. 16-24, 1999.

PINELLI, E.; RUTTEN, V. P. M. G.; RUITEMBERG, E. J. Celular immune responses in canine leishmaniasis. In: PROCEEDINGS OF THE INTERNATIONAL CANINE LEISHMANIOSIS, 1., 1999, Barcelona. Proceedings... Barcelona, Spain: Hoechst Roussel Vet, 1999. p. 60-64.
Leishmaniose visceral: breve revisão sobre uma zoonose reemergente. Revista Clínica Veterinária, São Paulo, v. 2 , n. 11, p. 24-28, 1997.

SILVA, R. M.; LAURENTI, M. D.; GOMES, A. C.; NOGUEIRA, Y. L. TG-ROC analysis of immunofluorescence assays in canine visceral leishmaniasis. Revista de Saúde Pública, São Paulo, v. 43, n. 6, p. 1-9, 2009.

SLAPPENDEL, R. J. Canine leishmaniasis. A review based on 95 cases in the Netherlands. Veterinary Quarterly, London, v. 10, n. 1, p. 1-16, 1988.

SLAPPENDEL, R. L.; FERRER, L. Leishmaniasis. In: GREENE, C. E. Infectious diseases of the dog and cat. 2. ed. Philadelphia: W.B. Saunders, 1998. p. 450-458.

TAFURI, W. G. L.; OLIVEIRA, M. R.; MELO, M. N.; TAFURI, W. L. Canine visceral leishmaniosis: a remarkable histopathologic picture of one case reported from Brazil. Veterinary Parasitology, Amsterdam, v. 96, n. 3, p. 203-212, 2001 .

TRAVI, B. L.; TABARES, C. J.; CADENA, H.; FERRO, C.; OSORIO, Y. Canine visceral leishmaniasis in Colômbia: relationship between clinical and parasitologic status and infectivity for sand flies. American Journal of Tropical Medicine and Hygiene, Baltimore, v. 64, n. 3-4, p. 119-124, 2001.

VILAGRAN, J. C. Leishmaniasis canina. In: MUR, E. S. Manual clinico de dermatología en el perro y gato. Barcelona: Pulso Ediciones, 1997. p. 229-237.

WORLD HEALTH ORGANIZATION - WHO. WHO expert committee on the control of the Leishmania. Geneva: WHO, 1990.

WOLSCHRIJN, C. F.; MEYER, H. P.; HAZEWINKEL, H. A. W.; WOLVEKAMP, W. Th. C. Destructive polyarthritis in a dog with leishmaniasis. Journal of Small Animal Practice, Oxford, v. 37, n. 12, p. 601-603, 1996.

ZANETTE, M. F. Comparação entreos métodos de ELISA, imunofluorescência indireta e imunocromatografia para o diagnóstico da leishmaniose visceral canina. 2006. Dissertação (Mestrado em Ciência Animal) - Curso de Medicina Veterinária da Universidade Estadual Paulista, Araçatuba.

SANTA ROSA, I. C. A.; OLIVEIRA, I. C. S. 
